\title{
LITERATURA MARGINAL: A GENEALOGIA DE UMA ESCRITA DE RESISTÊNCIA
}

\author{
MARGINAL LITERATURE: THE GENEALOGY OF \\ A RESISTANCE WRITING
}

\section{Luciana Coronel ${ }^{1}$}

Resumo: O estudo propõe uma genealogia para o fenômeno da "literatura marginal", que emerge no sistema literário brasileiro no início do século XXI a partir do agenciamento de Ferréz, ensejando embate fundamental na cena cultural contemporânea através da reivindicação de seus autores por reconhecimento como produtores de cultura. Tendo como o fundamento a concepção de Stuart Hall (2006), que vê no jogo das relações culturais "a luta de classes na cultura", propõe-se uma linhagem composta por autores historicamente identificados com a margem representada em seus textos. Entende-se ser Euclides da Cunha o primeiro autor nacional a propor, um século antes, uma escrita que se fazia instrumento de denúncia da opressão dos segmentos marginalizados de então, os sertanejos. Lima Barreto, Plínio Marcos e João Antônio oferecem ao longo do século XX uma mudança radical de perspectiva nessa série literária, passando a enunciar a resistência a partir do próprio espaço em que habitavam.

Palavras-chave: Ferréz; literatura empenhada; enunciação marginal.

Abstract: This study proposes a genealogy for the phenomenon of "marginal literature", which emerges in the Brazilian literary system in the beginning of the 21st century from the agency of Ferréz, giving rise to a fundamental clash in the contemporary cultural scene, through their author's claim for recognition as cultural producers. Based on the concept by Stuart Hall (2006), which sees in the game of cultural relations "the class struggle in culture", a lineage composed of authors historically identified with the margin represented in their texts is proposed. It is understood that Euclides da Cunha was the first national author to propose, a century before, a writing that became an instrument of denunciation of oppression for the marginalized segments of the time, the sertanejos. Lima Barreto, Plínio Marcos e João Antônio offer throughout the 20th century a radical change of perspective in this literary series, starting to enunciate resistance from the very space in which they lived.

Key words: Ferréz, committed literature, marginal enunciation.

1 Professora da Fundação Universidade de Rio Grande - FURG. E-mail: lu.paiva.coronel@gmail.com 
A marginalidade literária da produção negra não é uma opção estilística formal, ato contracultural, estilo de vida ou expressão de vanguarda, nesse momento. É a indissociabilidade de uma produção literária à situação de seu grupo cultural, a internalização dos fatores externos à obra. Mário Augusto da Silva

A consideração de Mário Augusto da Silva que abre este artigo, constante de seu monumental estudo A descoberta do insólito: literatura negra e literatura periférica no Brasil (1960-2000), indica uma condição marginal que se identifica não apenas com a produção literária de autores negros, a que é diretamente atribuída, mas se estende ao conjunto dos assim chamados autores periféricos, cuja origem social acaba por condicionar uma inserção desprestigiada no interior do sistema literário brasileiro contemporâneo hegemônico, internalizando-se no âmbito da cultura estigmas arraigados na vida social nacional desde os primórdios da colonização, ancorada na escravidão, e ainda não superados nos marcos de um Estado nacional republicano já centenário.

É, portanto, no longo processo de nossa própria formação social nacional e, mais especificamente, nos impasses que este Estado republicano desde os primórdios abarca, gerenciando conflitos sem jamais erradicar privilégios herdados do período escravista, perpetuados ainda que incompatíveis com a noção plena de espaço "público" que deveria representar, que encontramos a chave básica de entendimento da condição marginal de importantes autores da safra mais recente em relação ao cânone das letras nacionais, confirmando o entendimento do teórico jamaicano Stuart Hall acerca do que expressa o jogo das relações culturais: "a luta de classes na cultura" (HALL, 2006, p. 242).

Buscando entender as raízes da marginalidade literária atual, pode-se tomar a produção literária brasileira que emerge no alvorecer do século XX, na sequência da tentativa de implantação do que deveria ser uma res publica no país, e nesse contexto identificar, de acordo com João Camilo Penna, que "foi sem dúvida Euclides da Cunha quem flagrou, pela primeira vez, a topografia da margem e da marginalidade brasileira, sob a forma de uma dupla margem geográfico-histórica, a selva amazônica do alto Purus e a cidade sitiada de Canudos." (PENNA, In: FARIA; PENNA; PATROCINIO, 2015, p. 46) Deste modo, "o local histórico, matricial, da margem brasileira tem um nome: sertão." (PENNA, In: FARIA; PENNA; PATROCINIO, 2015, p. 48).

O sertanejo é, para Penna, o primeiro representante da margem no imaginário nacional contemporâneo, e esse estatuto marginal prolonga-se no presente. Euclides da Cunha foi o primeiro autor do século XX a aproximar a literatura da marginalidade social brasileira, revelando a consciência de um país dividido que o escritor percebeu não caber nas chaves conceituais que a formação de engenheiro militar adepto do progresso e da ciência lhe fornecia. Assim, as oposições correspondentes entre cidade e sertão, civilização e barbárie, não davam conta de explicar o que viu em Canudos, pois, se os sertanejos agiam de modo primário, não era diferente a conduta dos soldados, que os executavam em nome de uma ordem republicana que já se mostrava excludente e arbitrária.

A constatação de traços identitários comuns e compartilhados entre os que agiam em nome da cultura e da razão e seus adversários, considerados bárbaros e supersticiosos, é 
fundamental para a construção de um entendimento da literatura marginal que manifesta-se em solo nacional no século XXI para além do binarismo que propõe a margem em oposição ao centro, como zonas estanques e sem contato. Longe disso, a leitura que ora se apresenta da nova leva de autores que rasuram com sua rebeldia ideológica incontível a imagem de uma literatura comportada as entende como vozes que emergem da tensão permanente entre zonas de conflito na sociedade brasileira:

A formulação enunciativa desde a margem, longe de se compreender pelo processo opositivo com a ideia de centro ou cânone, está a serviço da constituição de um topos mais complexo, para o qual confluem forças estéticas, éticas e políticas, que, para além de configurarem um lugar a partir do qual se pode contestar o status quo, promove a ampliação de uma zona fronteiriça, de convivência tensa entre instâncias distintas da formação cultural brasileira [...]. (FARIA In FARIA; PENNA; PATROCINIO, 2015, p. 482).

Entendidas, assim, como portadoras de novas fagulhas de sentido que cruzam a fronteira dos sistemas culturais constituídos e em confronto na cena atual, as enunciações marginais no âmbito da literatura mais recente mostram-se reveladoras de conflitos que, muito longe de serem próprios de sua borda periférica, dizem respeito ao todo da vida social nacional. Walnice Nogueira Galvão (In CUNHA, 2004), em estudo crítico sobre Os sertões aponta exatamente para a necessidade de articulação dos gritos que emanavam da margem do arraial ao centro das instâncias privilegiadas do país, no sentido de compor uma totalidade histórica passível de abarcar os dois lados da moeda.

Para Walnice, as duas partes em luta na campanha de Canudos, soldados e sertanejos, sendo membros da mesma nacionalidade, sofriam a modernização em curso no país à época de modo radicalmente distinto: para os primeiros ela significava a abertura de inúmeras oportunidades de auto-desenvolvimento, enquanto para os outros, era a causa de dores e perdas irreparáveis, inclusive da vida, ceifada sem piedade quando colocavam-se no caminho do progresso:

Tanto Euclides acreditava na modernização que termina por condenar a guerra, no fecho do livro, dizendo que os canudenses deviam ter sido tratados à cartilha e não à bala, concluindo pela ilusão ilustrada de acreditar na educação como panacéia para a iniquidade. (GALVÃO In CUNHA, 2004, p. 4)

Em Os sertões revela-se, portanto, não apenas a violência brutal com que a jovem República decepava o futuro de seus filhos mais vulneráveis, dizimados para que a história do país avançasse a passos velozes sem que a noção de cidadania fosse ampliada e universalizada. Revelam-se também ali os defeitos estruturais da nascente modernização brasileira, que se mostrava já nos primórdios excludente, seletiva e concentradora de benefícios como em poucos lugares se viu. A denúncia da exclusão contida na voz da periferia do século XXI dá sequência a essa queixa, mostrando os desdobramentos perversos do processo modernizador no cenário presente. 
"A verdade [...] é subjetiva, provém menos dos fatos que de sua hermenêutica", essa é, segundo Massaud Moisés (2001, p. 227), a descoberta aterradora do engenheiro positivista Euclides da Cunha, testemunha ocular da História em um massacre perpetrado pelos segmentos esclarecidos contra os miseráveis tomados por fanáticos, pela arrogância de sua razão, que lhes impedia de enxergar as necessidades do outro e de entender "a verdade" contida nos clamores dessa alteridade. Moradores de favelas, morros, comunidades e presídios seguem sendo chacinados até os dias de hoje em razão do mesmo desconhecimento acerca da sua alteridade indesejável.

Se Euclides da Cunha tematizou pela primeira vez em Os sertões (1902) a margem no âmbito da literatura brasileira do século XX, não restam dúvidas de que foi Afonso Henriques de Lima Barreto o primeiro representante da margem urbana nacional, sendo etnicamente mestiço, socialmente pobre e ainda geograficamente suburbano, a inserir-se no seleto terreno dos escritores, com a publicação de Recordações do Escrivão Isaías Caminha (1909). A seu respeito, discorre a biógrafa Lilia Moritz Schwarcz:

\begin{abstract}
Afro-descendente por origem, opção e forma literária, Lima Barreto combateu todas as formas de racismo [...] e desenhou seus personagens com particular ternura. Eles eram diferentes daqueles que o público estava habituado a encontrar nos romances que faziam sucesso então. Suas religiões híbridas destoavam do catolicismo oficial e imperante; os protagonistas variavam nos tons expressos na cor da pele, e moravam em locais mais distantes do centro da cidade, que ressoavam um passado africano. Uma África afetiva e pessoal, "da margem de cá”, um continente imaginado e recriado no país. (SCHWARCZ, 2017, p. 10).
\end{abstract}

A militância exercida contra o preconceito racial através da literatura nos primórdios de uma República eugenista conformava-se, é sabido, por meio de personagens e enredos em que se reconhece a presença do espaço biográfico do autor. Tematizando "de dentro" a vida precária e sem glamour dos subúrbios cariocas, de que as belas letras de seu tempo não tratavam, e ainda se expressando por meio de uma linguagem fluente e desambiciosa, que, segundo Alfredo Bosi (1982, p. 360), oportunizou uma “descida de tom" muito benéfica à ficção em língua portuguesa, Lima Barreto teve recorrentemente negado o estatuto literário das suas produções, consideradas por muitos demasiado "jornalísticas". Esta herança maldita o patriarca dos marginais deixa como legado aos autores provenientes das margens atuais, nas quais também comparece a indissociabilidade entre o vivido e o narrado.

Tal aspecto já havia comparecido antes da emergência dos autores autointitulados "marginais" na escrita de Carolina Maria de Jesus, que, com Quarto de despejo: diário de uma favelada (1960), deu continuidade à saga de escritores alijados da literariedade devido à sobreposição de uma origem social desprestigiada às formas de uma enunciação autoral profundamente enraizada na vivência no espaço de um espaço marginal. Ainda que sua obra conformasse a seu modo uma denúncia das condições de vida miseráveis dos habitantes das favelas, boa parte deles sendo afro-descendentes migrados do nordeste do país, dificilmente a mesma seria identificada com a pauta da literatura marginal que surgiria cerca de quarenta anos depois, em razão da ausência na mesma de um enraizamento identitário na margem como fundamento do texto: 
Um termo injurioso constitui uma sociabilidade negativa; este mesmo termo pode, no entanto, ser abraçado, saudado, afirmado, e utilizado estrategicamente para nomear um coletivo ativo e ativista, militante. O termo é utilizado pela afirmação localizada, apropria-se de sua herança negativa, inverte o estigma. [...] Apropriar-se dele é inverter o sentido da injúria, é transformar a marca do estigma em marca de circulação de um coletivo. O bonde chamado desejo. (PENNA In: TENNINA; MEDEIROS; PEÇANHA; HAPKE, 2015, p. 14).

A ressignificação do termo "marginal” é o fundamento identitário dessa nova safra de autores, como em Carolina não é. ${ }^{2}$ Ele passa a ser adotado com orgulho pelo coletivo liderado por Ferréz desde o "Manifesto Terrorista", que abre o conjunto de edições especiais sobre Literatura Marginal, lançadas pela revista Caros Amigos e intituladas "Caros Amigos/Literatura Marginal: a cultura da periferia”, publicadas nos anos de 2001, 2002 e 2004. Partindo dessas edições, Ferréz publicou o livro Literatura marginal: talentos da escrita periférica (2005), marco de afirmação de uma nova forma de enunciação literária, como se verá a seguir.

Antes desse episódio de absorção e processamento criativo das marcas da discriminação historicamente sofrida pelo povo das bordas urbanas, que elabora síntese nova de uma condição subalternizada, houve no contexto histórico brasileiro contemporâneo outras ocorrências da reivindicação por uma condição marginal no terreno das letras nacionais, como a de Plínio Marcos e João Antonio, que trazem no bojo de sua criação o fio comum da incontível vocação para transgredir padrões e cruzar a borda da área de permanência autorizada pelo stablishment.

Enraizados em uma condição social desfavorecida, autores como Plínio Marcos e João Antonio trariam à cena no período da ditadura militar representações de uma marginalidade sofrida pela dinâmica de uma sociedade excludente e autoritária. Uma marginalidade inescapável para a qual buscam, cada um a seu modo, as formas de expressão. Uma marginalidade que não deixa de ser por eles conhecida, sendo ambos residentes em zonas periféricas e companheiros próximos dos dramas de vida que identificam seus personagens.

Tematizando "as quebradas do mundaréu" por meio de cenas em espaços como a prisão, os prostíbulos, as ruas, nos quais vasta gama de personagens vive a opressão e a miséria econômica e afetiva, Plínio Marcos encarna ele próprio o papel de maior personagem marginal que pudera alguma vez criar, tendo sido funileiro, ator de circo, jogador de futebol, entre outras atividades antes de se dedicar à literatura, ao teatro e à crônica, nos quais consagrou-se em vida sem jamais abandonar o compromisso de fé com os perdedores da sociedade:

Não me deixem sozinho agora que estou com mais do que mereço, meus amigos e irmãos. Superem meu temperamento difícil, meu modo agressivo, e não me deixem sozinho. Não me deixem, nem por um minuto, mudar o meu rumo, me confundir, me enroscar, me levar a sério, acreditar no nome do jornal. Agora, mais do que nunca, eu preciso dos perdedores do meu lado, preciso dos encar-

2 Discuti esse tópico em artigos como "O direito de sonhar em Carolina Maria de Jesus”. Ver nas referências finais. 
cerados, dos perseguidos, preciso dos cassados e dos impedidos de participar da vida nacional. Preciso dos que anseiam por justiça e dos desesperançados. Preciso dos famintos e dos enfermos. Preciso dos meus fantasmas de sempre. Porque eu não quero nada sem estar com eles. (MARCOS apud CONTRERAS; MAIA; PINHEIRO, 2002, s/p).

João Antonio, discípulo confesso de Lima Barreto, a quem dedicou todos os seus livros, tematizou nos mesmos a geografia física e humana das margens urbanas, protagonizada pelos trabalhadores e malandros, em jogos de sinuca, prostíbulos e botequins, onde transcorre a vida desregrada do submundo da boemia suburbana. Morador desse espaço e autor empenhado em traduzir sua imagem em literatura, o autor de Abraçado ao meu rancor é citado por Ferréz, ligando os pontos entre sua literatura e a dos autores periféricos do século XXI e delineando mais um ponto da linhagem marginal encabeçada por Lima Barreto:

Evitem certos tipos, certos ambientes. Evitem a fala do povo, que vocês nem sabem onde mora e como. Não reportem povo, que ele fede. Não contem ruas, vidas, paixões violentas. Não se metam com o restolho que vocês não vêem humanidade ali. Que vocês não percebem vida ali. E vocês não sabem escrever essas coisas. Não podem sentir certas emoções, como o ouvido humano não percebe ultra-sons. (ANTONIO apud FERRÉZ, 2005, p. 14).

Ainda que Ferréz se coloque em continuidade com a proposta de João Antonio, baseada na reivindicação de uma autenticidade advinda da experiência nas margens como base da criação literária sobre os marginalizados, João Cézar de Castro Rocha lê a emergência de personagens da nova safra marginal de autores encabeçada por Ferréz em ruptura com a assim chamada "dialética da malandragem" (originalmente presente no ensaio crítico de Antonio Candido sobre Memórias de um sargente de Milícias, de Manuel Antonio de Almeida) e constitutiva do universo simbólico do autor de Malagueta, perus e bacanaço, notabilizado pela maestria com que pintou os malandros no cenário paulista em seu ocaso histórico.

A “dialética da marginalidade", segundo o critico e professor da UERJ, seria uma forma emergente de compreensão do país, oriunda de representações desvinculadas da velha lógica da conciliação por meio de uma crítica certeira da desigualdade social que teria em Cidade de Deus (1997), de Paulo Lins, o seu ponto de eclosão. A hipótese de uma disputa simbólica entre ambas as dialéticas baseia-se na presença de um teor inédito de violência avassaladora como elemento central da representação da sociedade em obras recentes, boa parte das quais identificadas com o rótulo de "marginal". Desenhando uma imagem de destruição implacável dos laços de sociabilidade baseados na cordialidade, o modelo da dialética da marginalidade pressupõe uma nova forma de relacionamento entre as classes sociais:

Não se trata mais de conciliar diferenças, mas de evidenciá-las, recusando-se a improvável promessa de meio-termo entre o pequeno círculo dos donos do poder e o crescente universo dos excluídos. Nesse contexto, o termo marginal não possui conotação unicamente pejorativa, representando também o contingente 
da população que se encontra à margem, no tocante aos direitos mais elementares, sem dispor de uma perspectiva clara de absorção, ao contrário do malandro. (ROCHA, 2004)

A evidência de diferenças sociais e a impossibilidade da conciliação de classes são nítidas no manifesto “Terrorismo literário” (2001), através do qual Ferréz anuncia a emergência da Literatura marginal no sistema literário nacional. O termo é oriundo da canção "Capítulo 4 versículo 3", do grupo de rap Racionais Mc's, cuja letra diz: “[...] Eu tenho uma missão e não vou parar/ Meu estilo é pesado e faz tremer o chão/ Minha palavra vale um tiro... eu tenho muita munição." Em seguida se apresenta o "terrorista da periferia", identificado com a "fúria negra, [que] ressuscita outra vez" no ano de 1997 D.C., ano do lançamento do cd Sobrevivendo no inferno, no qual encontra-se a canção (RACIONAIS MC’S, 1997).

O termo "terrorismo" na certidão de fundação desta vertente literária aponta para a ideia de missão política conjugada ao uso da violência, ainda que se trate de uma violência de teor simbólico, pois é a palavra que "vale um tiro", trata-se de uma "palavra arma", a ser empunhada pelos autores "marginais" em sua escrita que ataca o stablishment literário, avisando aos seus gestores, críticos especializados, produtores culturais variados e mesmo aos leitores: "não precisamos da sua legitimação, porque não batemos na porta para alguém abrir, nós arrombamos a porta e entramos. (FERRÉZ, 2005, p. 10).

É notória a sintonia da proposta agressiva da literatura marginal com o rap, sobretudo com o grupo Racionais MC's, que, segundo Maria Rita Kehl, é capaz de "simbolizar a experiência de desamparo destes milhões de periféricos urbanos, de forçar a barra para que a cara deles seja definitivamente incluída no retrato atual do país (um retrato que ainda se pretende doce, gentil, miscigenado), de produzir uma fala significativa e nova sobre a exclusão." (KEHL, 2000, p.215).

Tomando de assalto a cena literária, o líder e agenciador dos autores da periferia reforça, por um lado, o imaginário usualmente atribuído à marginalidade, recorrendo a um léxico que costuma acompanhar as representações da marginalidade, violência, tiros e armas. Por outro lado, aspira a contrariar o estigma hegemonicamente atribuído ao termo, dignificando a condição que se abriga no mesmo. Assim, Ferréz lança mão de uma estratégia de deslizamento de sentido, tornando o conceito autorreferido uma espécie de medalha, que se porta com orgulho, principalmente porque se trata de uma identidade "marginal" compartilhada, impregnada do sentido de irmandade.

Dispensando o selo da aprovação daqueles que estão no centro da vida literária, ele os coloca à margem dos seus interesses: "a própria linguagem margeando e não os da margem, marginalizando e não os marginalizados” (FERRÉZ, 2005, p. 9). Esta literatura faz das margens o centro de uma nova forma de produção escrita, marginalizando o centro da vida cultural e pretendendo-se autônoma e dotada de força propulsora própria, calcada nas injustiças seculares de nosso país: "Somos o contra sua opinião, não viveremos ou morreremos se não tivermos o selo da aceitação, na verdade, tudo vai continuar, muitos querendo ou não." (FERRÉZ, 2005, p. 9).

Sem deixar de trazer as marcas da verossimilhança realista, os textos dos autores marginais que despontam no início do século XXI não se encaixam exatamente nos moldes da 
convenção realista herdada do século XIX. Trata-se, segundo os organizadores de Modos de margem: figurações da marginalidade na literatura brasileira, de um "realismo experiencial": "o que se lê são experiências vividas, mesmo e sobretudo quando reconstruídas ficcionalmente.” (FARIA; PENNA; PATROCÍNIO, 2015, p. 20).

É inequívoca a dimensão utópica presente nessa enunciação proveniente das zonas de pobreza e exclusão, que ambiciona mais do que a representação simbólica da experiência de vida nesta região brutalmente inóspita, ambiciona atuar em prol de sua transformação: "Literatura de rua, com sentido, sim, com um princípio, sim, e com um ideal sim, trazer melhoras para o povo que constroi esse país mas não recebe sua parte." (FERRÉZ, 2005, p. 10). Segundo o criador do selo "marginal”, esta especificação não constitui uma opção, mas deriva de uma constatação lúcida acerca do funcionamento excludente do campo cultural hegemônico:

\section{Cansei de ouvir:}

Mas o que cês tão fazendo é separar a literatura, a do gueto e a do centro.

E nunca cansarei de responder:

- O barato já tá separado há muito tempo, só que do lado de cá ninguém chegou com a nossa parte, foi feito todo um mundo de teses e de estudos do lado de lá, e do cá, mal terminamos o ensino dito básico. (FERRÉZ, 2005, p. 13).

A literatura marginal inaugura, portanto, a perspectiva da margem como locus inédito de enunciação literária no país. Não por meio de uma separação segregadora de si em um gueto, mas por meio de um rótulo de diferenciação que evidenciaria, segundo seu criador, a divisão existente na sociedade, que seria replicada no âmbito da criação literária, independente da vontade de seus protagonistas. Érica Peçanha do Nascimento, estudiosa da literatura de periferia, define em Vozes marginais na literatura brasileira contemporânea que o isolamento é traço central da identidade dos textos marginais: "A ideia essencialista de uma cultura da periferia, defendida pelos escritores estudados, e exclusiva dos moradores das periferias, pressupõe um mundo à parte.” (NASCIMENTO, 2009, p. 56).

A periferia não é, no entanto, um mundo à parte. Ela é a parte mais vulnerável da cidade, mas faz parte desta. É o outro lado da riqueza concentrada no centro. A cidade é uma só, mesmo que as diferenças sociais criem um muro de segregação em sua paisagem. O essencialismo contido na identidade "marginal" é, portanto, uma inteligente estratégia discursiva de diferenciação destes autores em um todo maior no qual dificilmente teriam visibilidade sem um nome impactante, capaz de lhes dar destaque.

Trata-se, assim, de uma interessantíssima maneira de inserção em um meio elitista e discriminador como o literário. O termo "marginal", ainda que ancorado em uma opressão secular em nossa história, não aponta, no entanto, para uma condição fixa, imutável, mas para um estado provisório e contingente, passível de manutenção ou não dependendo das disputas que se travam no interior do sistema literário pelos diferentes sujeitos enunciado- 
res e da capacidade de cada um de se impor. Ocorre que muitas vezes sujeitos autorais marginais ou mesmo suas formas e temas sejam absorvidos pelas mídias hegemônicas.

Boaventura de Souza Santos discorre acerca desse processo: "A diferença cultural subverte as ideias de unidade e uniformidade culturais na medida em que se afirma a partir de práticas enunciativas que são vorazes em relação aos diferentes universos culturais de que se servem." (SANTOS, 2010, p. 237). Fora de qualquer unidade ou uniformidade, pensamos os textos de Literatura Marginal como enunciados que, se podem ser abarcados pela dinâmica dos sistemas culturais dominantes, por sua vez constituem-se vazados de todos os lados pelas marcas dos diferentes sistemas culturais que compõem a vida urbana contemporânea, na qual está incluída a periferia.

$\mathrm{Na}$ escrita das margens estão representados, portanto, de modos variados e com distintas formas de expressão, temas específicos como a violência, o tráfico, a precariedade de serviços básicos, a força da religiosidade popular de matriz africana, as gírias da oralidade periférica, mas também temas mais amplos, pertinentes à sociedade contemporânea em seu todo, tais como a dinâmica consumista da televisão, os termos que compõem o idioma maior da informática, dos games e das redes sociais.

Não poderia ser de outra forma, uma vez que "as crises da literatura e da sociedade de classes são irmãs" (SCHWARZ, 1979, p. 147). Se a sociedade abarca em seu seio a população que constroi a riqueza do país, e ao mesmo tempo a renega enquanto conjunto de cidadãos capazes de produzir arte e cultura, a literatura que esta produz não poderia deixar de expressar esse desajuste e essa sede de empoderamento da parte de uma leva de autores que, a partir de 2000, ousam lançar ao país seu grito coletivo nos moldes de um "mutirão de palavras". (RODRIGUEZ, 2003).

Uma vez que não há a margem como locus estanque de enunciação, estamos todos implicados na dinâmica literária na qual a literatura marginal emerge e busca legitimação. Este artigo pretendeu ser um gesto simbólico de promoção dessas vozes, que falam por si e dispensam mediadores, mas cuja dicção pode ser expandida no terreno da vida acadêmica por meio de sujeitos pesquisadores empenhados na luta por uma cena literária mais democrática, mais inclusiva e mais utópica.

O crítico Flávio Aguiar, partindo do olhar auspicioso de Franklin Oliveira, acreditou ser possível desentranhar uma leitura de esperança de Os sertões, de Euclides da Cunha, escritor apontado como o ponto de partida da linhagem identificada com a temática das vozes marginais na literatura brasileira no limiar do século XX. Em um momento nacional repleto de angústia e susto como este que vivemos, a breve apresentação das vozes marginais que fizemos não pretende mais do que alinhar-se à vertente da crítica literária empenhada nesta insistência teimosa da esperança, por isso recorre a suas palavras: "A leitura aqui proposta retoma o possível fio de esperança. Não mais que fio, não mais que possível. Porém não menos." (AGUIAR, 1999, p. 170).

O fio de esperança possível parece hoje tênue, quase invisível. Mas não nos resta outro caminho para construir qualquer perspectiva de futuro. Por isso nele apostamos neste estudo, que resgata a linhagem dos autores identificados primeiramente com a temática marginal e na sequência com a enunciação marginal propriamente dita, alimentando o sonho de uma cultura inclusiva e plural neste país avariado pelos ventos da intolerância e do autoritarismo. 


\section{Referências bibliográficas}

AGUIAR, Flávio. A volta da serpente. Língua e literatura, n. 25. São Paulo: Humanitas/FFLCH/USP, 1999, p. 169-189. Disponível em https://www.revistas.usp.br/linguaeliteratura/issue/view/7915/375. Acesso em: 10 set. 2021.

BOSI, Alfredo. História concisa da literatura brasileira. São Paulo: Cultrix, 1982.

CONTRERAS, Javier; MAIA, Fred; PINHEIRO, Vinícius. Plínio Marcos: a crônica dos que não tem voz. São Paulo: Boitempo editorial, 2002.

CORONEL, Luciana. O direito de sonhar em Carolina Maria de Jesus. In: DALCASTAGNÈ, Regina; LICARÃO, Berttoni; NAKAGOME, Patrícia. Literatura e resistência. Porto Alegre, Zouk, 2018, p. 111125.

FARIA, João Alexandre. A margem como utopia - a ginga na poesia de Allan da Rosa In: FARIA, João Alexandre; PENNA, João Camilo; PATROCINIO, Paulo Roberto Tonani. Modos de margem: figurações da marginalidade na literatura brasileira. Rio de Janeiro: Aeroplano, 2015, p. 482-502.

FERRÉZ. Terrorismo literário. In: FERRÉZ (org.). Literatura marginal: talentos da escrita periférica. Rio de Janeiro: Agir, 2005, p9-14.

GALVÃO, Walnice Nogueira. In: CUNHA, Euclides da. Os sertões: Campanha de Canudos. 2.ed. São Paulo: Ática, 2004.

HALL, Stuart. Que negro é esse na cultura negra?. In: HALL, Stuart. Da diáspora: identidades e mediações culturais. org. Liv Sovik, trad. Adelaine La Guardia Resende, Belo Horizonte: Ed. UFMG, 2006, p. 317-330.

JESUS, Carolina Maria de. Quarto de despejo: diário de uma favelada. 6.ed., São Paulo: Francisco Alves, 1960. (Contrastes e conforntos, v. 1)

JESUS, Carolina Maria de. Quarto de despejo: diário de uma favelada. 3.ed., São Paulo: Ática, 1994.

JESUS, Carolina Maria de. Quarto de despejo: diário de uma favelada. 9.ed., São Paulo: Ática, 2007.

KEHL, Maria Rita. A fatria orfã: o esforço civilizatório no rap na periferia de São Paulo. In: KEHL, Maria Rita (org.). Função fraterna. Rio de Janeiro: Relume-Dumará, 2000, p. 209-244.

MOISÉS, Massaud. História da Literatura brasileira. Vol II: Realismo e Simbolismo. São Paulo: Cultrix, 2001.

NASCIMENTO, Érica Pessanha do. Vozes marginais na literatura brasileira contemporânea. Rio de 
Janeiro: Aeroplano, 2009.

PENNA, João Camilo. Jagunços, topologia, tipologia. In: FARIA, João Alexandre, PENNA, João Camilo, PATROCINIO, Paulo Roberto Tonani. Modos de margem: figurações da marginalidade na literatura brasileira. Rio de Janeiro: Aeroplano, 2015, p. 46-75.

PENNA, João Camilo. Margem entrevista. In: TENNINA, Lucía, MEDEIROS, Mário; PEÇANHA, Érica; HAPKE, Ingrid. Polifonias marginais. Rio de Janeiro: Aeroplano, 2015, p. 13-19.

RACIONAIS MC’S. Capítulo 4 versículo 3. In: RACIONAIS MC’S. Sobrevivendo no inferno. CD, São Paulo: Gravadora Cosa Nostra, 1997. Disponível em: http://www.vagalume.com.br/racionais-mcs/capitulo-4 versiculo.html\#ixzz2j1cMBjlA. Acesso em: 30 set. 2021.

ROCHA, João Cézar de Castro. Dialética da marginalidade: caracterização da cultura brasileira contemporânea. Folha de São Paulo. Caderno Mais, 29 fev. 2004. Disponível em: https://www1.folha. uol.com.br/fsp/mais/fs2902200404.htm. Acesso em: 04 maio 2012.

RODRIGUEZ, Benito Martinez. Mutirões da palavra: literatura e vida comunitária nas periferias urbanas. Estudos de Literatura Brasileira Contemporânea, n. 22. Brasília, p. 47-61, jan./jun. 2003.

SANTOS, Boaventura de Souza. A gramática do tempo: para uma nova cultura política. 3.ed., São Paulo: Cortez, 2010. (para um novo senso comum, v. 4)

SCHWARZ, Roberto. Pressupostos, salvo engano, da “Dialética da malandragem”. In: ARINOS, Afonso et alii (org.). Esboço de figura: homenagem a Antonio Candido. São Paulo: Livraria Duas Cidades, 1979, p.147.

SILVA, Mário Augusto Medeiros da. A descoberta do insólito: literatura negra e literatura periférica no Brasil (1960-2000). Rio de Janeiro: Aeroplano, 2013. 
